\title{
Development of rapid advice guideline and standard and continuous updating guideline: experiences and practice
}

\author{
Ying-Hui Jin $^{1 \dagger}$, Xiao-Mei $\mathrm{Yao}^{2 \dagger}$ and Xian-Tao Zeng ${ }^{1,3^{*}}$ (10
}

\begin{abstract}
We published rapid advice guidelines and updated guidelines for coronavirus disease 2019 (COVID-19) management on February 6, 2020, and September 4, 2020, respectively. These two guidelines vary widely in their developmental background, type of evidence, grade of recommendation and so on. We shared our experience for the development of these two guidelines to help clinical practitioners better understand and implement guidelines and to help guideline developers facilitate communication and discussion for guideline development during the pandemic.
\end{abstract}

Keywords: COVID-19, SARS-CoV-2, Rapid advice guideline, Clinical practice guideline, Evidence-based medicine

\section{Dear Editor,}

Early in 2020, during the novel coronavirus infection outbreak, we published a rapid advice guideline for the diagnosis and treatment of coronavirus disease 2019 (COVID-19; Guideline 1, https://mmrjournal. biomedcentral.com/articles/10.1186/s40779-020-0233-6 \#citeas) [1]. Later, in September 2020, we registered and published an updated guideline named "Chemoprophylaxis, diagnosis, treatments, and discharge management of COVID-19: An evidence-based clinical practice guideline (updated version)" (Guideline 2, https://mmrjournal. biomedcentral.com/articles/10.1186/s40779-020-00270-8) $[2,3]$. These two guidelines were both prepared in accordance with the methodology and general rules of World

This comment refers to the article available at https://doi.org/10.1186/ s40779-020-00270-8. This comment refers to the article available at https:// doi.org/10.1186/s40779-020-0233-6.

*Correspondence: zengxiantao1128@163.com; zengxiantao1128@whu.edu.cn ${ }^{+}$Ying-Hui Jin and Xiao-Mei Yao contributed equally to this work.

${ }^{1}$ Center for Evidence-Based and Translational Medicine, Zhongnan Hospital of Wuhan University, Wuhan 430071, China

${ }^{3}$ Department of Urology, Zhongnan Hospital of Wuhan University, 169 Donghu Road, Wuchang District, Wuhan 430071, China

Full list of author information is available at the end of the article
Health Organization (WHO) Guideline Development [4]. The WHO Rapid Advice Guidelines advice was used in the development of Guideline 1, and the guideline was issued within 1 week. We convened multidisciplinary guideline development groups composed of health professionals (experts in respiratory medicine, infectious disease, critical care medicine, cardiology, emergency medicine, pediatrics, oncology, gerontology, laboratory medicine, medical imaging, clinical immunology, and clinical pharmacy) and methodologists for developing both guidelines.

For any newly identified infection, an absolute lack of direct evidence is the greatest challenge for guideline developers. Thus, for Guideline 1, we were totally reliant on indirect evidence, such as that for severe acute respiratory syndrome (SARS), Middle East respiratory syndrome (MERS), and influenza. Although research has reported that severe acute respiratory syndrome coronavirus 2 (SARS-CoV-2), which causes COVID-19, is similar to SARS-CoV (approximately $80 \%$ similar), the evidence for the possible benefits of treatment in patients with SARS or MERS disease was considered indirect because the patient populations, viruses, and possibly 
even drug effects were different. Therefore, the rating of the quality of evidence for all important efficacy outcomes was downgraded by two levels based on the Grading of Recommendations Assessment, Development and Evaluation (GRADE) approach [4]. Indirect evidence that played an important role in guideline development during the early stage of the epidemic gradually faded when direct evidence on COVID-19 appeared.

The COVID-19 pandemic is a rapidly changing situation. An increasing number of research papers are being published both in China and internationally, providing research evidence for managing COVID-19, which enabled direct evidence from COVID-19 patients to be used in the development of Guideline 2. Guideline 2 finally included 75 original papers (including 12 randomized controlled trials) and 33 systematic reviews or meta-analyses.

During the Guideline 1 development process, 11,500 symptomatic persons were screened, 276 were identified as suspected victims of infection, and 170 were diagnosed (including 33 in critical condition) as having COVID-19 by the guideline working group's clinical professionals. Frontline clinicians have accumulated valuable experience in the diagnosis, treatment and nursing of COVID-19 patients. There was no direct research evidence to inform recommendations at that time, and these experiences were assessed as "expert evidence" for our guideline development. Expert evidence was highly valued in Guideline 1 development. We used a structured form to collect this information so that it could be aggregated and presented to the guideline panel in the summary of findings. Expert evidence can be solicited by examining case reports, summaries, and reports of topics. During the consensus process, if the evidence was agreed upon by more than $70 \%$ of frontline clinicians, it was considered high-quality evidence. However, "expert evidence" was used slightly differently in the development of Guideline 2. Expert evidence would not change the direction and strength of recommendations based on direct evidence, but it could influence questions that have very limited evidence and may form an "ungraded consensus-based statement" when more than $70 \%$ of working group members in the guideline panel believed this conclusion to be valid.

In the development of Guidelines 1 and 2, we adhered to the GRADE approaches and rules to assess the quality of a body of evidence [5], to develop and report recommendations, and to make some adjustments. First, assessments of the quality of the evidence that were not for pooled estimates of effect were available as a narrative synthesis of the evidence in the development of Guideline 1. Second, as COVID-19 spreads worldwide, there is an increasing number of ongoing trials, resulting in new research papers being published, possibly every day. We downgraded the quality of evidence for imprecision based on the threshold that represents the basis for a management decision rather than considering whether an optimal information size was reached. Third, rigorous search techniques were implemented in the development of Guideline 2; therefore, we thought the possibility of unidentified studies leading to publication bias was rare. Fourth, for diagnostic questions, studies measuring the impact of testing on patient-important or populationimportant outcomes were not available; hence, the guideline panels included only studies with diagnostic test accuracy outcomes, which were considered a surrogate outcome for patient-important benefits and harm. Last, despite very low evidence or only having expert evidence suggesting benefit in a life-threatening situation, strong recommendations may be warranted. For example, no clinical trials have demonstrated the benefit of the application of mechanical ventilation or its indications for use. However, as a common clinical life support and rescue method, mechanical ventilation is often used in life-threatening situations.

All guidelines need to be kept up to date and consistent with the best available evidence [6]. This is particularly important but difficult to achieve in the context of a public health emergency, such as COVID-19, when new data are constantly emerging and experience is continually accruing [7]. Although we updated Guideline 2 recently, its recommendations will require continuous updating in the future to incorporate increasingly highquality direct evidence.

\section{Conclusions}

Guidelines of all types should always be evidence-based. It is a common misunderstanding that evidence-based guidelines can be developed only if well- designed controlled trials exist. Recommendations are derived from a systematic review of evidence, which is the current best evidence, and guidelines in a pandemic are no exception. The guidelines should be updated with continuously emerging evidence.

\section{Abbreviations}

COVID-19: Coronavirus disease 2019; GRADE: Grading of Recommendations Assessment, Development and Evaluation; MERS: Middle East respiratory syndrome; SARS: Severe acute respiratory syndrome; SARS-CoV-2: Severe acute respiratory syndrome coronavirus 2

\section{Acknowledgments}

Not applicable.

\section{Authors' contributions}

XMY and XTZ designed this letter, YHJ collected and analyzed the data, XMY and $\mathrm{YHJ}$ drafted this letter, and XTZ reviewed this letter. All authors read and approved the final manuscript.

\section{Funding}

This work was supported in part by the Entrusted Project of National Center for Medical Service Administration, National Health and Family Planning 
Commission China (No. [2019]099), and the Emergency Special Project for COVID-19 of Wuhan Municipal Health Commission (EG20A02).

\section{Availability of data and materials}

Not applicable.

Ethics approval and consent to participate

Not applicable.

\section{Consent for publication}

Not applicable.

\section{Competing interests}

The authors declare that they have no competing interests.

\section{Author details}

${ }^{1}$ Center for Evidence-Based and Translational Medicine, Zhongnan Hospital of Wuhan University, Wuhan 430071, China. ${ }^{2}$ Department of Health Research, Evidence and Impact, McMaster University, Hamilton, Ontario L8S 4L8,

Canada. ${ }^{3}$ Department of Urology, Zhongnan Hospital of Wuhan University,

169 Donghu Road, Wuchang District, Wuhan 430071, China.

Received: 5 November 2020 Accepted: 11 January 2021

Published online: 03 February 2021

\section{References}

1. Jin YH, Cai L, Cheng ZS, Cheng H, Deng T, Fan YP, et al. A rapid advice guideline for the diagnosis and treatment of 2019 novel coronavirus (2019nCoV) infected pneumonia (standard version). Mil Med Res. 2020;7:4.

2. Jin $Y H$, Li HJ, Zhan QY, Peng ZY, Yuan YF, Cai L, et al. Evidence-based Chinese expert recommendations on drug prevention, diagnosis, treatment, and discharge management of COVID-19: a protocol. Yixue Xinzhi Zazhi. 2020;30(3):209-26.

3. Jin YH, Zhan QY, Peng ZY, Ren XQ, Yin XT, Cai L, et al. Chemoprophylaxis, diagnosis, treatments, and discharge management of COVID-19: an evidence-based clinical practice guideline (updated version). Mil Med Res. 2020;7:41.

4. World Health Organization. WHO handbook for guideline development. 2nd ed; 2014. [Accessed 22 Jan 2020]. Available from: https://apps.who.int/iris/ handle/10665/145714

5. Cochrane Training. GRADE Handbook. In: Schünemann H, Brożek J, Guyatt G, Andrew Oxman A, editors [Updated October 2013, Accessed 10 Mar 2020]. Available from: https://gdt.gradepro.org/app/handbook/handbook. html.

6. Yao X, Jin YH, Djulbegovic B. Some thoughts on conducting and implementing clinical practice guidelines in a pandemic. Chin Med J. 2021. https://doi.org/10.1097/CM9.0000000000001169 Ahead of Print.

7. Norris SL. Meeting public health needs in emergencies-World Health Organization guidelines. J Evid Based Med. 2018;11(3):133-5.

Ready to submit your research? Choose BMC and benefit from:

- fast, convenient online submission

- thorough peer review by experienced researchers in your field

- rapid publication on acceptance

- support for research data, including large and complex data types

- gold Open Access which fosters wider collaboration and increased citations

- maximum visibility for your research: over $100 \mathrm{M}$ website views per year

At BMC, research is always in progress.

Learn more biomedcentral.com/submissions 